\title{
Large pulmonary artery pseudoaneurysm in mucormycosis: successfully managed with surgery and amphotericin
}

\author{
Valliappan Muthu, ${ }^{1}$ Harkant Singh, ${ }^{2}$ Ujjwal Gorsi, ${ }^{3}$ Ritesh Agarwal ${ }^{1}$
}

${ }^{1}$ Pulmonary Medicine, Postgraduate Institute of Medical Education and Research, Chandigarh, India ${ }^{2}$ Cardiovascular and Thoracic Surgery, Postgraduate Institute of Medical Education and Research, Chandigarh, India ${ }^{3}$ Radiology, Postgraduate Institute of Medical Education and Research, Chandigarh, India

\section{Correspondence to Dr Valliappan Muthu; valliappa@gmail.com}

Accepted 30 December 2020

\section{DESCRIPTION}

A 54-year-old woman with poorly controlled diabetes mellitus presented with haemoptysis $>400 \mathrm{~mL}$ over the last 12 hours. She had been experiencing fever and a productive cough for the past 20 days. She was a non-smoker and had no other illness in the past other than diabetes mellitus. CT of the chest revealed thick-walled cavities in the right upper and middle lobes; a reversed halo sign (RHS) was seen in the right middle lobe (figure 1A). CT pulmonary angiography showed a large pulmonary artery pseudoaneurysm (PAP; $3 \times 2.7 \times 2.5 \mathrm{~cm}$ ) in the cavity situated in the right lower lobe (figure 1B). Complete blood count revealed haemoglobin of $9 \mathrm{~g} / \mathrm{dL}$, the renal and liver functions were normal. Flexible bronchoscopy revealed a clot in the right lower lobe. Sputum and bronchoalveolar lavage fluid did not reveal any organism. She was treated with broad-spectrum antibiotics and liposomal amphotericin B $(3 \mathrm{mg} / \mathrm{kg})$ in view of a high likelihood of pulmonary mucormycosis (PM). Right pneumonectomy was performed 5 days after hospitalisation. The postoperative specimen revealed multiple cavities and a large PAP in the right lower lobe. Microscopic examination confirmed the diagnosis of PM (figure 2A,B). The patient was extubated 2 days after surgery and discharged from the hospital after completing 18 days of amphotericin. One-month after the discharge, she was well with no recurrence of fever or haemoptysis and the chest radiograph demonstrated post-pneumonectomy status.

PAP is rarely reported in PM and usually has an unfavourable outcome. ${ }^{1-3}$ In a case series of 32 cases with PM, PAP was observed in one subject. ${ }^{4}$ The recommended treatment for mucormycosis is liposomal amphotericin B and surgery. While the newer triazoles may have a favourable adverse effect profile, the evidence supporting their use is limited. Transcatheter embolisation

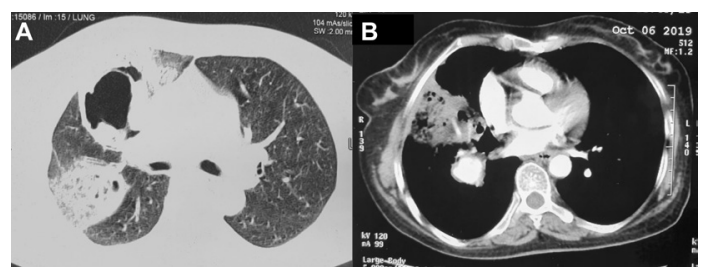

Figure 1 CT showing (A) cavity and reversed halo sign in the right lung and (B) a large pulmonary artery pseudoaneurysm on the right side.

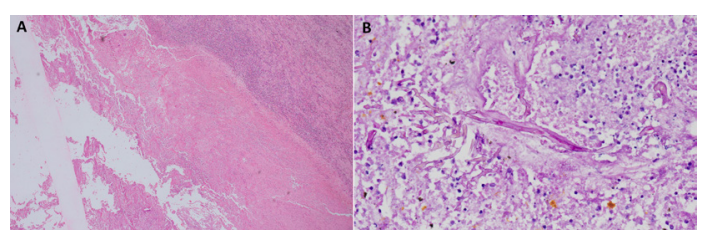

Figure 2 Photomicrographs showing (A) lung cavity with necrotic material $(\mathrm{H} \& \mathrm{E}$ stain, $\times 40)$ and $(\mathrm{B})$ numerous aseptate thin-walled foldable fungal hyphae in the necrotic cavity (Periodic acid-Schiff (PAS) stain, $\times 400$ ).

has been tried with varying success in few cases of PAP due to mucormycosis. ${ }^{35}$ While there is a role of endovascular treatments in a small arterial aneurysm, they rarely offer a cure in cases of large pseudoaneurysms due to PM. ${ }^{6}$ The embolisation of PAP can be considered as a bridge for definitive surgery.

Surgery has a definitive role and improves survival in patients with PM. Several patients with PM present with diabetic ketoacidosis, hence timely medical management and stabilisation, followed by surgery within 1-2 weeks of amphotericin therapy is essential. However, large PAP is at risk for rupture and imminent death. In such a scenario, an early surgery (as in our case) may be useful.

Early diagnosis of PM is important since a delay in antifungal is associated with high mortality. A high index of suspicion is required, and timely initiation of antifungal therapy is warranted in the presence of clinicopathologic suspicion of PM. In our index case, a microbiologic or pathologic diagnosis could not be obtained preoperatively, and amphotericin was started based on the imaging finding of RHS in a poorly controlled diabetic. $^{78}$

\section{Learning points}

- Large pulmonary artery pseudoaneurysm is an uncommon complication of pulmonary mucormycosis and usually presents as massive haemoptysis.

- A high index of suspicion is required to diagnose pulmonary mucormycosis.

- Timely amphotericin B therapy and surgery can be lifesaving. 
In conclusion, PAP is a rare complication of PM, and timely amphotericin-B and surgery were lifesaving.

Acknowledgements Dr Amanjit Bal (Professor, Department of Histopathology) for the histopathology of surgical specimen and providing the photomicrographs of the same.

Contributors VM-Conceived the idea, drafted the manuscript and involved in patient management. HS and UG - Involved in patient management, reviewed and approved the manuscript. RA—Involved in patient management, drafted, reviewed and approved the manuscript.

Funding The authors have not declared a specific grant for this research from any funding agency in the public, commercial or not-for-profit sectors.

Competing interests None declared.

Patient consent for publication Obtained.

Provenance and peer review Not commissioned; externally peer reviewed.

\section{REFERENCES}

1 Souza LVS, Souza AS, Marchiori E. Mucormycotic pulmonary pseudoaneurysm causing fatal hemoptysis. Arch Bronconeumol 2019;55:597-8.

2 Lopez-Pastorini A, Koryllos A, Brockmann M, et al. Pseudoaneurysm of the pulmonary artery with massive haemoptysis due to an invasive pulmonary mucormycosis. Thorax 2016:71:199-200.

3 Economopoulos N, Kelekis D, Papadopoulos A, et al. Subclavian artery occlusion and pseudoaneurysm caused by lung apex mucormycosis: successful treatment with transcatheter embolization. Cardiovasc Intervent Radiol 2007;30:143-5.

4 McAdams HP, Rosado de Christenson M, Strollo DC, et al. Pulmonary mucormycosis: radiologic findings in 32 cases. AJR Am J Roentgenol 1997;168:1541-8.

5 Mempin R, Kamangar N. Pulmonary artery pseudoaneurysm due to mucormycosis: case report and literature review. J Clin Imaging Sci 2020;10:55.

6 Lal A, Bansal A, Chaluvashetty SB, et al. Percutaneous transthoracic embolisation for massive haemoptysis secondary to peripheral pulmonary artery pseudoaneurysms. Eur Radiol 2020. doi:10.1007/s00330-020-07348-w. [Epub ahead of print: 03 Oct 2020].

7 Muthu V, Dhooria S, Singh Sehgal I, et al. The reversed halo sign and the bronchus sign: the eyes see only what the mind knows. Ann Am Thorac Soc 2019;16:1203.

8 Maturu VN, Agarwal R. Reversed halo sign: a systematic review. Respir Care 2014;59:1440-9.

Copyright 2021 BMJ Publishing Group. All rights reserved. For permission to reuse any of this content visit

https://www.bmj.com/company/products-services/rights-and-licensing/permissions/

BMJ Case Report Fellows may re-use this article for personal use and teaching without any further permission.

Become a Fellow of BMJ Case Reports today and you can:

- Submit as many cases as you like

- Enjoy fast sympathetic peer review and rapid publication of accepted articles

- Access all the published articles

- Re-use any of the published material for personal use and teaching without further permission

Customer Service

If you have any further queries about your subscription, please contact our customer services team on +44 (0) 2071111105 or via email at support@bmj.com.

Visit casereports.bmj.com for more articles like this and to become a Fellow 